\title{
Relationship of the Gas Temperature Distribution with the Descending Rate and Layer Thickness of Burden in the Throat of Blast Furnace*
}

\author{
By Kiichi NARITA,** Shin-ichi INABA,** Isao KOBAYASHI, ** Ken-ichi OKIMOTO,** \\ Masakata SHIMIZU,** Keiji KUWANO*** and Koichi IKEDA***
}

\begin{abstract}
Synopsis
The operation data of a blast furnace have been analyzed.

The gas temperature distribution in the throat of blast furnace is divided into two patterns. One is named the spire type, in which the temperature is extremely high only in the central narrow part. Another is named the hill type, in which the temperature is high over the wide region of the center.

The gas temperature distribution seems to be closely related to the descending rate of burden. For the spire type, the descending rate measured by a charging level probe is faster than the average rate calculated from the charging volume of burden. For the hill type, in which the measured rate is slower than the average, the descending rate in the central part is thought to be faster than the average.

The difference in the descending rates at the central and the peripheral parts results in the variation of the distribution of ore to coke ratio in the stack. The variation of the layer thickness of burden in the throat is theoretically calculated considering the distribution of descending rate.

The distribution pattern of top gas temperature is closely related to the thermal condition of blast furnace, and its change usually occurs 6 to $10 \mathrm{hr}$ before the beginning of variation in the temperature of pig iron.
\end{abstract}

\section{Introduction}

Recently, with an increase in blast furnace volume, the throat diameter has become larger. Therefore, the control of radial distributions of burden and gas flow in the furnace has become more and more important. ${ }^{1)}$

Radial distribution of gas temperature over the stack has been studied, and it is reported that an extremely high temperature only in the central narrow part is desirable for the stable operation. ${ }^{2,3)}$

This temperature pattern seems to be influenced by the burden distribution and the profile of softening-cohesive zone in the furnace. In this work, the relation between the temperature distribution and various data on the furnace behavior has been investigated. It is found that the layer thicknesses of charged ore and coke are varied by the burden descending rate measured by a charging level probe, and this rate seems to have a radial distribution. Then, considering the radial distribution of the descending rate, theoretical analysis on the layer thickness has been made.

Furthermore, it is confirmed that the gas temperature pattern at the throat relates closely to the thermal condition of the furnace, especially to the temperature of hot metal. By monitoring this pattern, the control of thermal condition has become possible.

\section{Distribution Pattern of Gas Temperature at the Throat}

The radial distribution of gas temperature was studied at Kakogawa No. 2 blast furnace $(13.2 \mathrm{~m}$ hearth diameter and $3850 \mathrm{~m}^{3}$ inner volume) in Kobe Steel, Ltd.

On the stable furnace performance, two kinds of patterns were observed as shown in Fig. 1. One is named the spire type, in which the temperature is extremely high only in the central narrow part. Another is named the hill type, in which the temperature is high over the wide region of the center.

In order to express these patterns, the following Gaussian distribution function is applied.

$$
T_{i}=C_{1} \cdot \exp \left(-\frac{r^{2}}{2 C_{2}^{2}}\right)+T_{w}
$$

Constants $C_{1}$ and $C_{2}$ are obtained by substituting the observed temperatures at $r=0$ and $r=1$ into Eq. (1), and $G T_{1}$ index is defined as Eq. (2).

$$
G T_{1}=\left(C_{1} / C_{2}\right) / T_{1}
$$

As shown in Fig. 1, GT 1 becomes larger as the temperature pattern shifts from the hill type to the spire type.

Functuation of blast pressure is written as follows : ${ }^{4}$ )

$$
F=\left(\sum_{i=1}^{n} \Delta P_{i}\right) / n
$$

where, $\Delta P_{i}=P_{B, i}-P_{B, i-1}$

$i$ : sampling number

$n$ : sum of samples

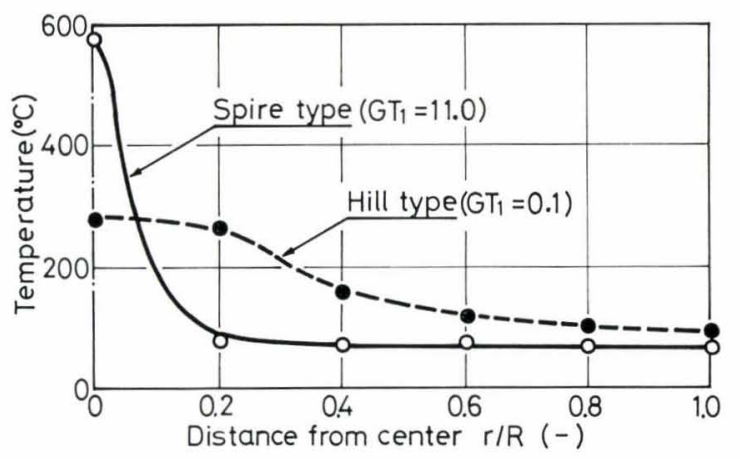

Fig. 1. Typical patterns of temperature distribution of gas at throat

\footnotetext{
* Originally published in Tetsu-to-Hagané, 65 (1979), 44, in Japanese. English version received February 5, 1979.

** Central Research Laboratory, Kobe Steel, Ltd., Wakinohama-cho, Fukiai-ku, Kobe 651.

*** Kakogawa Works, Kobe Steel, Ltd., Kanazawa-cho, Kakogawa 675-01.
} 
When $F<10$, the furnace behavior was quite stable, and no breakage of tuyeres took place.

Figure 2 shows the relationship between $G \mathcal{T}_{1}$ and $F$. It is seen that here are two regions of $G T_{1}<1$ and $G T_{1}>7$ for $F<10$. In the case of $G T_{1}>7$, which is the spire type, the productivity could be increased and the stable operation was able to be maintained. On the other hand, for $G T_{1}<1$, which is the hill type, the gas utilization and the thermal efficiency fell down in spite of a small fluctuation of blast pressure.

\section{Relation between the Temperature Pattern and Burden Descending Rate}

The relation between $G T_{1}$ and the descending rate of burden at the periphery was examined.

The average descending rate is expressed as follows,

$$
v_{a v}=\mathcal{N} \cdot \mathrm{C}_{\mathrm{B}} \cdot\left\{\frac{1}{\rho_{\mathrm{e}}}+\frac{(\mathrm{O} / \mathrm{C})}{\rho_{\mathrm{o}}}\right\} /(24 \times A)
$$

The symbol $v^{*}$ is defined as the ratio of the peripheral descending rate $\left(v_{w}\right)$ measured by a charging level probe to the average one $\left(v_{a v}\right)$.

$$
v^{*}=v_{w} / v_{a v}
$$

Figure 3 shows the relation between $G T_{1}$ and $v^{*}$. For $G T_{1}<1$ and $7<G T_{1}$, $v^{*}$ becomes larger. Besides, $v^{*}$ for $7<G T_{1}$ is larger than that for $G T_{1}<1$.

Figure 4 shows the relationship between the layer thicknesses of charged ore and coke and $v^{*}$. Each thickness is presented by the following dimensionless term:

$$
l_{\mathrm{c}}^{*}=l_{\mathrm{c}} / l_{\mathrm{c}, a v}, \quad l_{\mathrm{o}}^{*}=l_{\mathrm{o}} / l_{\mathrm{o}, a v}
$$

where $l_{\mathrm{c}}$ and $l_{\mathrm{o}}$ are measured by a charging level probe and $l_{\mathrm{c}, a v}$ and $l_{\mathrm{o}, a v}$ are the average ones, respectively. It is seen that $l_{\mathrm{o}}^{*}$ and $l_{\mathrm{c}}^{*}$ are increased with $v^{*}$, that is, each layer becomes thicker with an increase in descending rate at the periphery. Furthermore, from the regression coefficient, it is noted

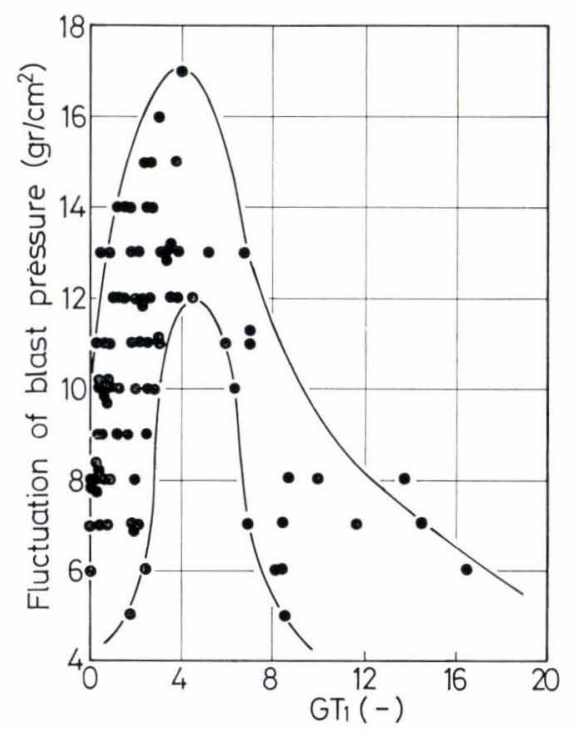

Fig. 2. Relationship betweem temperature distribution in$\operatorname{dex} G T_{1}$ and fluctuation of blast pressure that the increasing ratio of $l_{0}^{*}$ is larger than that of $l_{c}^{*}$, and that the ore/coke ratio at the periphery should be changed with $v^{*}$.

\section{Radial Distribution of Burden Descending}

In Fig. 5, the actual production rate of pig iron is compared with the one calculated from the peripheral descending rate measured by a charging level probe. If the peripheral descending rate is equal to the average descending rate, the calculated quantity should agree with the actual one. The calculated value is, however, often larger than the actual one, that is, the peripheral descending rate is faster than the average. This implies that there exists a region of descending rate slower than the average. Assuming that the rate distribution of burden descent is linear to the radius, the region of slower descending rate

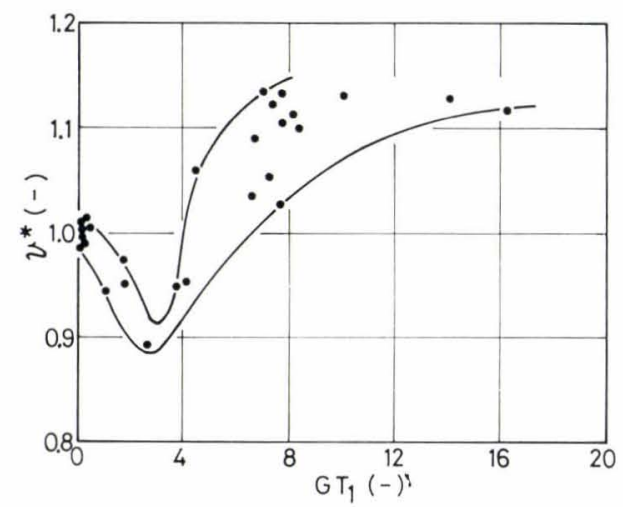

Fig. 3. Relationship between temperature distribution in$\operatorname{dex} G T_{1}$ and specific descending rate $v^{*}$

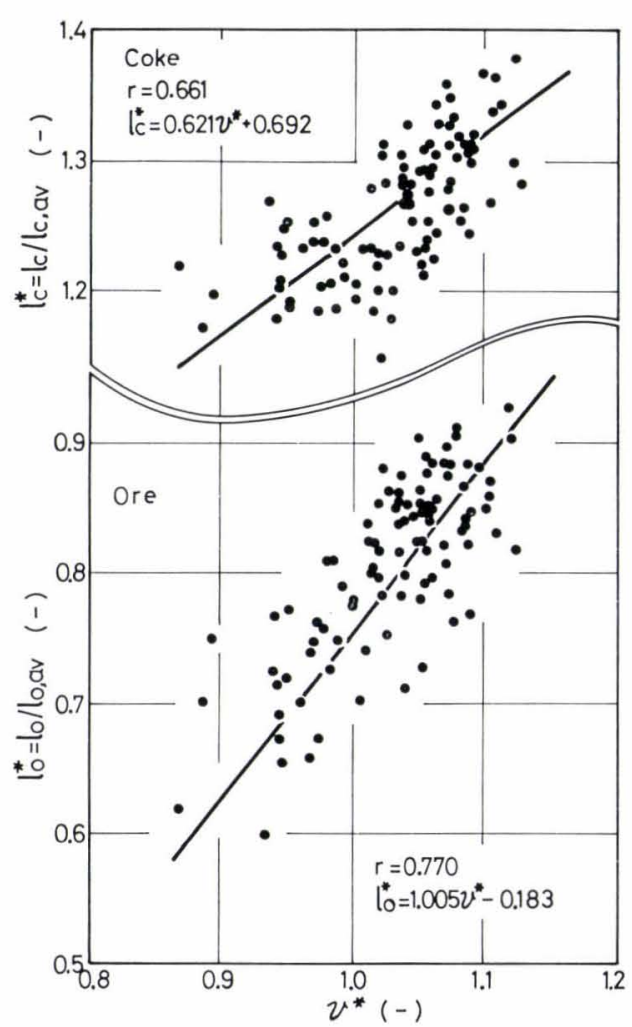

Fig. 4. Relationship between specific descending rate $v^{*}$ and layer thickness $l_{\mathrm{o}}^{*}, l_{\mathrm{c}}^{*}$ 


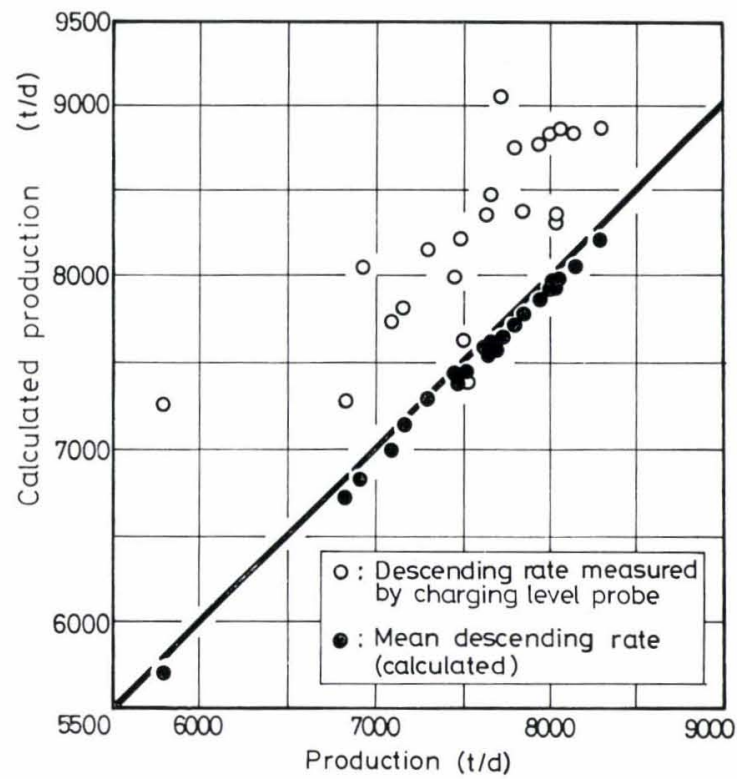

Fig. 5. Comparison of calculated production with actual production

Table 1. The operation data at different descending rate

\begin{tabular}{l|cc}
\hline \multicolumn{1}{c|}{ Period } & A & B \\
\hline Item & 13 & 18 \\
\hline Slope angle $\left({ }^{\circ}\right)$ & 8.42 & 7.54 \\
$v_{w} \quad(\mathrm{~m} / \mathrm{h})$ & 8.00 & 7.50 \\
$v_{\text {av } \quad(\mathrm{m} / \mathrm{h})}$ & 3.66 & 3.72 \\
ore $/$ coke & 7920 & 7872 \\
Bosh gas volume & & \\
$(\mathrm{Nm} / \mathrm{min})$ & 86.4 & 82.6 \\
Sol. loss C & & \\
$(\mathrm{kg} / \mathrm{t}-\mathrm{p})$ &
\end{tabular}

Gas temp. pattern
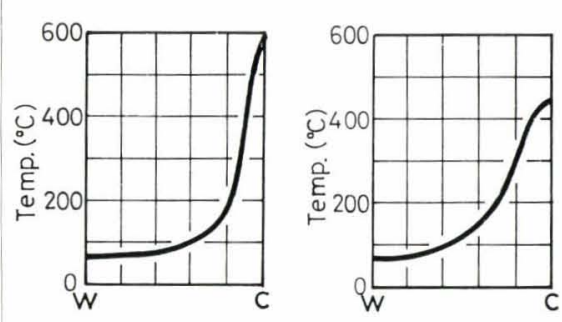

should exist in the center and the inclination of the burden surface should become smaller before the next charge.

Surface inclinations of ore were measured in both periods of the spire type and the hill type of the temperature profile at Kakogawa No. 2 blast frunace when the furnace was shut-down. These results and the operational data just before the shutting-down are presented in Table 1. Both operating conditions were quite similar, and each delay time from the shuttingdown to the measuring was taken equally in order to compare the results directly.

In both periods, the inclinations are rather smaller than the repose angle of ore $\left(21^{\circ}\right)$. In the period $\mathrm{A}$, in which the temperature profile showed the typical spire type, the peripheral descending rate is faster than the average, and the inclination of the burden surface is smaller.

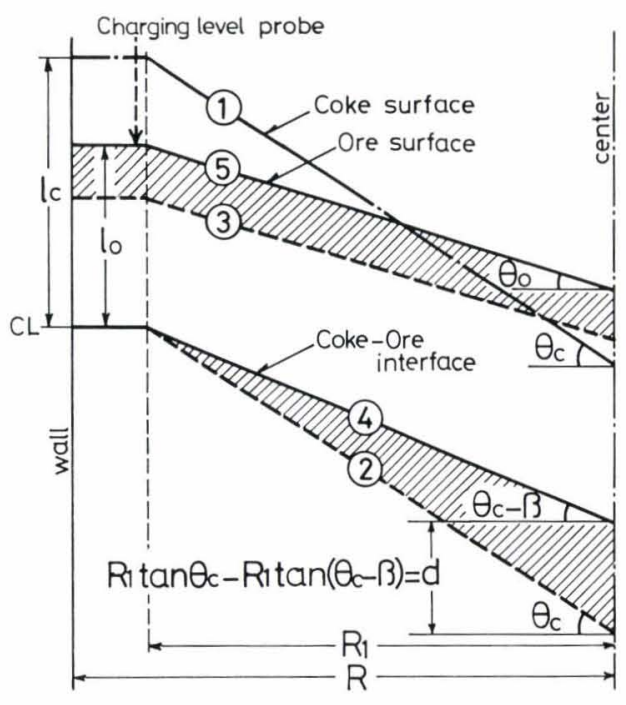

Fig. 6. A schematic diagram of layer thickness when $v_{w}>v_{c}$

In the period $B$, in which the temperature profile inclines to the hill type, the descending rates of the peripheral and the average are nearly equal. The inclination is larger than that of period $\mathrm{A}$; this value is close to the surface angle of the burden containing pellets, which has been obtained from the full-size model experiment. ${ }^{5)}$

\section{Theoretical Analysis on the Thickness of Charged Layer Considering the Radial De- scending Rate}

Based on the experiments of burden distribution and burden descending, and the observation in the shutdown period of the furnace, theoretical analysis has been made under the following conditions.

(1) The charging sequence is $\mathrm{C} \downarrow \mathrm{O} \downarrow$, where, the symbol $\downarrow$ expresses that a burden is dumped and the next material is not dumped until the stack surface reaches the charging level (CL).

(2) The surface profile at the throat forms the Mshape as shown in Fig. 6, and the material volume is kept constant during the burden descending.

(3) The radial distribution of burden descent is expressed as follows:

$$
\begin{aligned}
& v(r)=\left(v_{w}-v_{c}\right) \cdot r / R_{1}+v_{c} \quad\left(0 \leqq r \leqq R_{1}\right) \\
& v(r)=v_{w} \quad\left(R_{1} \leqq r \leqq R\right)
\end{aligned}
$$

(4) In the case of the descending rate of the center faster than that of the periphery $\left(v_{c}>v_{w}\right)$, ore slides into the central part, and the inclination of the surface is kept constant.

(5) No coke slides into the center, and the mixed layer of ore and coke is not formed by ore dumping.

\section{Layer Thickness in Case of $v_{w}>v_{c}$}

Figure 6 shows a schematic sketch to calculate the layer thickness. Each surface of charged layer shows the following situation.

(1) Coke surface just after dumping 
(2) Coke surface on reaching CL after descending in parallel

(3) Ore surface just after dumping on the coke surface (2)

(4) Coke surface at the time when a charging level probe on the surface (1) reaches CL in the case of $v_{w}>v_{c}$

(5) Ore surface just after dumping on the surface (4) (It is noted that the layer thickness should increase by the volume corresponding to the shaded area.)

From Fig. 6, the volume of charged ore is expressed as Eq. (6).

$$
V_{\mathrm{o}}=\pi R^{2} l_{\mathrm{o}}-\left(\pi R_{1}^{3} / 3\right)\left\{\tan \theta_{\mathrm{o}}-\tan \left(\theta_{\mathrm{c}}-\beta\right)\right\}
$$

The inclination of coke surface $\left(\theta_{c}-\beta\right)$ just before ore dumping is written as Eq. (7) by using the descending rate.

$$
\begin{aligned}
\tan \left(\theta_{\mathrm{c}}-\beta\right) & =\tan \theta_{\mathrm{c}}+\left(l_{\mathrm{c}} / R_{1}\right)\left(v_{c}-v_{w}\right) / v_{w} \\
& =\tan \theta_{\mathrm{c}}+\left(l_{\mathrm{c}} / R_{1}\right) \cdot \Delta v \ldots \ldots \ldots \ldots
\end{aligned}
$$

where, $\Delta v\left[=\left(v_{c}-v_{w}\right) / v_{w}\right]$ which is the dimensionless parameter representing the distribution of the burden descent.

Substituting Eq. (7) to Eq. (6) and dividing by the throat area, the thickness of ore layer is obtained as Eq. (8).

$$
l_{\mathrm{o}}=l_{\mathrm{o}, a v}-\mathrm{P}\left(R_{1} \cdot \Delta \theta+l_{\mathrm{c}} \cdot \Delta v\right)
$$

As to the coke layer, by the analogous treatment, Eq. (9) is obtained.

$$
l_{\mathrm{c}}=l_{\mathrm{c}, a v}+\mathrm{P}\left(R_{1} \cdot \Delta \theta-l_{\mathrm{o}} \cdot \Delta v\right)
$$

From Eqs. (8) and (9), each layer thickness $\left(l_{\mathrm{o}}, l_{\mathrm{c}}\right)$ is solved as follows:

$$
\begin{aligned}
& l_{\mathrm{o}}=\frac{\left(l_{\mathrm{c}, a v}+\mathrm{P} \cdot R_{1} \cdot \Delta \theta\right) \cdot \mathrm{P} \cdot \Delta v-\left(l_{\mathrm{o}, a v}-\mathrm{P} \cdot R_{1} \cdot \Delta \theta\right)}{(\mathrm{P} \cdot \Delta v)^{2}-1} . \\
& l_{\mathrm{c}}=\frac{\left(l_{\mathrm{o}, a v}-\mathrm{P} \cdot R_{1} \cdot \Delta \theta\right) \cdot \mathrm{P} \cdot \Delta v-\left(l_{\mathrm{c}, a v}+\mathrm{P} \cdot R_{1} \cdot \Delta \theta\right)}{(\mathrm{P} \cdot \Delta v)^{2}-1} .
\end{aligned}
$$

where,

$$
\begin{aligned}
& \mathrm{P}=\left(R_{1} / R\right)^{2} / 3 \quad(-), \quad l_{\mathrm{o}, a v}=V_{\mathrm{o}} / \pi R^{2}(\mathrm{~m}) \\
& \Delta \theta=\tan \theta_{\mathrm{c}}-\tan \theta_{\mathrm{o}} \quad(-), \quad l_{\mathrm{c}, a v}=V_{\mathrm{c}} / \pi R^{2}(\mathrm{~m}) \\
& \Delta v=\left(v_{c} / v_{w}\right)-1 \quad(-)
\end{aligned}
$$

Figure 7 shows the layer thickness calculated from Eqs. (10) and (11). It is seen that both peripheral thicknesses of coke and ore layers increase with a decrease in $\Delta v$, that is, with the peripheral descending rate faster than that of the center.

\section{Layer Thickness in the Case of $v_{c}>v_{w}$}

According to the sketches shown in Fig. 8, the layer thickness of the every charging stage has been formulated.

1. Thickness of Coke Layer just after Dumping (Fig. 8(a))

From the assumption that the inclination of ore surface is kept constant due to the sliding of ore into the center, the next charge of coke should be piled on the ore surface of angle $\theta_{\mathrm{o}}$. The layer thicknesses of the peripheral and the center are expressed as Eqs. (12) and (13).

$$
\begin{aligned}
& l_{\mathrm{c}}=\left(V_{\mathrm{c}}+\pi R_{1}^{3} \cdot \Delta \theta / 3\right) /\left(\pi R^{2}\right) \\
& l_{\mathrm{c}}^{\prime}=l_{\mathrm{c}}-R_{1} \cdot \Delta \theta \quad \ldots \ldots \ldots \ldots \ldots \ldots \ldots \ldots
\end{aligned}
$$

2. Thickness of Ore Layer just after Dumping (Fig. 8 (c))

The inclination of coke surface increases from $\theta_{c}$ to $\left(\theta_{\mathrm{c}}+\beta\right)$ with the burden descent. Then, the next ore is charged with the angle on the coke surface of which the inclination is $\left(\theta_{\mathrm{c}}+\beta\right)$. The volume of ore layer is written as Eq. (14).

$$
V_{\mathrm{o}}=\pi R^{2} l_{\mathrm{o}}(0)-\left(\pi R_{1}^{3} / 3\right)\left\{\tan \theta_{\mathrm{o}}-\tan \left(\theta_{\mathrm{c}}+\beta\right)\right\}
$$

With the same procedure as the derivation of Eq. (8), the peripheral and the central layer thicknesses are
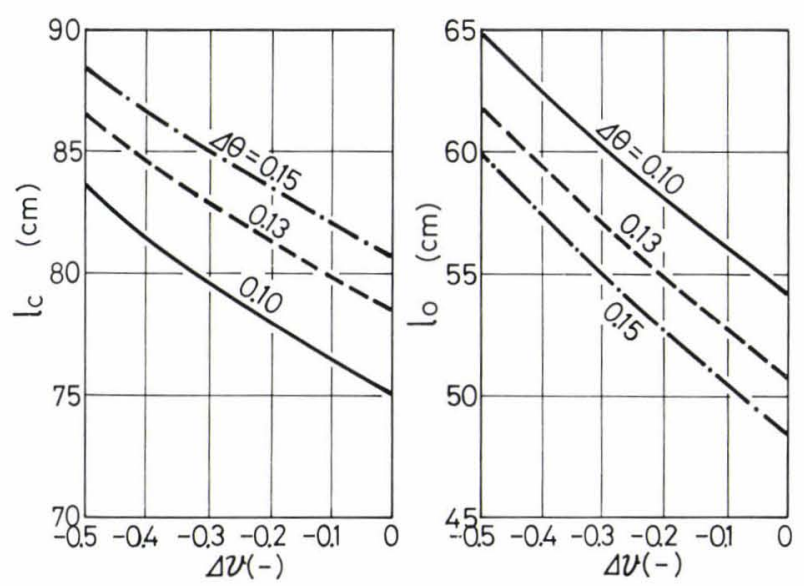

Fig. 7. Relationship between $\Delta v$ and layer thickness in periphery (coke base: 25 t, O/C: 3.7, Dia. at throat: $10.0 \mathrm{~m}$ )

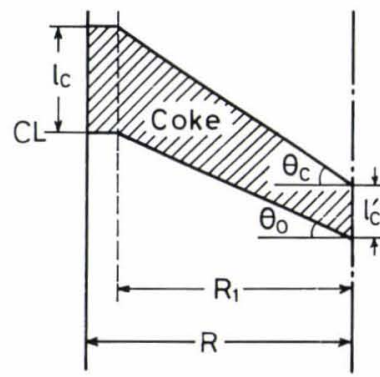

(a) after Ct

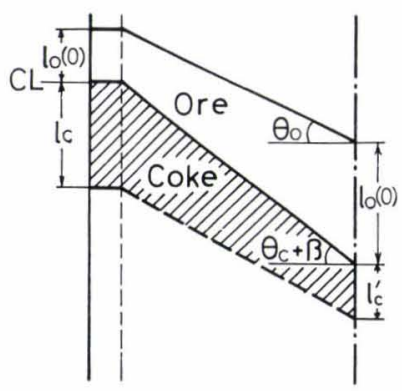

(C) after O†

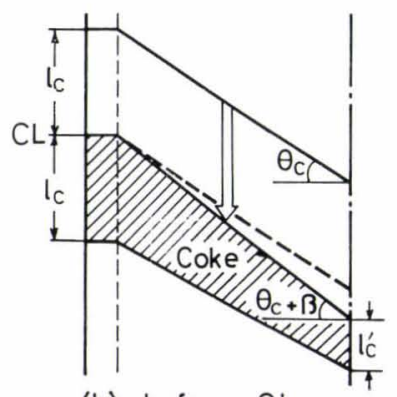

(b) before Ot

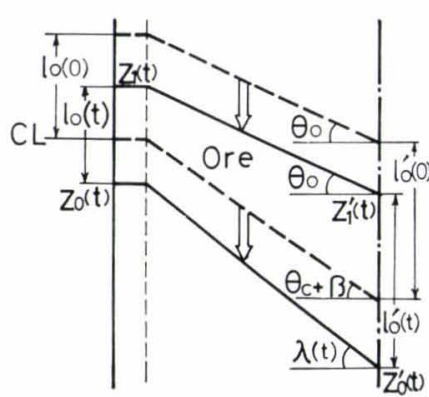

(d) thickness variation with descending
Fig. 8. Schematic diagrams of layer thickness when $v_{w}<v_{c}$ 
derived as Eqs. (15) and (16).

$$
\begin{array}{r}
l_{0}(0)=l_{0, a v}-(1 / 3)\left(R_{1} / R\right)^{2}\left(l_{\mathrm{c}} \cdot \Delta v+R_{1} \cdot \Delta \theta\right) \ldots \ldots .(15) \\
l_{0}^{\prime}(0)=l_{0}(0)+l_{\mathrm{c}} \cdot \Delta v+R_{1} \cdot \Delta \theta \ldots \ldots \ldots \ldots \ldots .(16)
\end{array}
$$

3. Change of Ore Layer Thickness (Fig. 8 (d))

The change of the inclination at the bottom surface of ore layer can be related to the descending rate as follows:

$$
\tan \lambda(t)=\tan \left(\theta_{\mathrm{c}}+\beta\right)+\left(v_{c}-v_{w}\right) t / R_{1}
$$

From the assumption of no volume change, the volume of ore layer is expressed as Eq. (18).

$$
V_{\mathrm{o}}=\pi R^{2} \cdot l_{\mathrm{o}}(t)-\left(\pi R_{1}^{3} / 3\right)\left\{\tan \theta_{0}-\tan \lambda(t)\right\} \ldots
$$

By substituting Eq. (17) into Eq. (18) and subtracting Eq. (14), the change of the peripheral layer thickness of charged ore is finally derived as Eq. (19).

$$
l_{\mathrm{o}}(t)=l_{\mathrm{o}}(0)-(1 / 3)\left(R_{1} / R\right)^{2}\left(v_{c}-v_{w}\right) \cdot t
$$

The layer thickness in the center is derived as Eq. (20) by applying Eqs. (17) and (19) to the geometrical relation which is shown in Fig. 8(d).

$$
l_{\mathrm{o}}^{\prime}(t)=l_{\mathrm{o}}^{\prime}(0)+\left\{1-(1 / 3)\left(R_{1} / R\right)^{2}\right\}\left(v_{c}-v_{w}\right) \cdot t \ldots
$$

\section{Ore Layer Thickness on Reaching CL}

The time $\left(t_{0}\right)$ that the peripheral surface of ore layer takes to reach CL, is evaluated from Eq. (21).

$$
\begin{aligned}
l_{\mathrm{o}}(0) & =\left\{v_{w}+\left|d l_{\mathrm{o}}(t) / d t\right|\right\} t_{0} \\
& =\left\{v_{w}+(1 / 3)\left(R_{1} / R\right)^{2}\left(v_{c}-v_{w}\right)\right\} t_{0}
\end{aligned}
$$

It is noted that the descending rate which is indicated by a charging level probe is the apparent one and is faster than the real descending rate $\left(v_{w}\right)$ by $(1 / 3)\left(R_{1} / R\right)^{2}\left(v_{c}-v_{w}\right)$. Substituting $t_{0}$ obtained from Eq. (21) into Eqs. (19) and (20), the layer thicknesses on reaching CL are derived as Eqs. (22) and (23).

$$
\begin{aligned}
l_{\mathrm{o}}\left(t_{0}\right)= & l_{\mathrm{o}}(0) /\left\{1+(1 / 3)\left(R_{1} / R\right)^{2} \cdot \Delta v\right\} \\
l_{\mathrm{o}}^{\prime}\left(t_{0}\right)= & l_{\mathrm{o}}^{\prime}(0)+\left\{1-(1 / 3)\left(R_{1} / R\right)^{2}\right\} \cdot \Delta v \\
& \times l_{\mathrm{o}}(0) /\left\{1+(1 / 3)\left(R_{1} / R\right)^{2} \cdot \Delta v\right\}
\end{aligned}
$$

Figure 9 shows the relation between $\Delta v$ and the layer thickness calculated from Eqs. (15), (16), (22) and (23). The full line represents the thickness just after dumping, the broken line designates the thick-
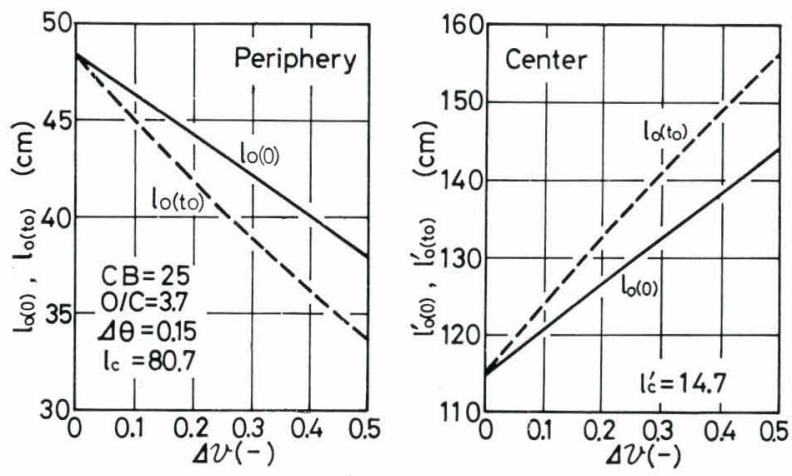

Fig. 9. Relation between $\Delta v$ and layer thickness of ore when $v_{w}<v_{c}$ ness on reaching $\mathrm{CL}$ with the sliding of ore into the center. It is seen that $l_{0}(0)$ decreases with an increase in $\Delta v$ (that is, an increase in descending rate in the center) and $l_{\mathrm{o}}^{\prime}(0)$ increases reversely. Comparing the thickness just after dumping with that of reaching CL at the same $\Delta v$, it is found that the layer thickness at the periphery is decreased from full line $\left(l_{\mathrm{o}}(0)\right)$ to broken line $\left(l_{\mathrm{o}}\left(t_{0}\right)\right)$ by the sliding of ore into the center, and the thickness at the center is increased in the opposite way. The volume sliding into the center is so increased with $\Delta v$ that the difference between $l_{\mathrm{o}}(0)$ and $l_{\mathrm{o}}\left(t_{0}\right)$ should become larger.

\section{Ore Volume Sliding into the Center}

According to Fig. 10, the ore volume sliding into the center has been estimated. Figure 10 shows the following states. Ore surface just after dumping from a large bell forms the profile $\mathrm{A}_{0} \mathrm{~B}_{0} \mathrm{C}_{0}$ and the peripheral layer thickness is $l_{\mathrm{o}}(0)$. Assuming that the inclination of ore surface is maintained at constant owing to the sliding of ore into the center, the surface should show the profile $\mathrm{A}_{2} \mathrm{~B}_{2} \mathrm{C}_{2}$ when reaching $\mathrm{CL}$ after $t_{0}$ hours. On the other hand, in the case of nosliding of ore into the center, the peripheral surface would be located at the point $\mathrm{B}_{1}$ after $t_{0}$ hours, and the surface would show the profile $\mathrm{A}_{1} \mathrm{~B}_{1} \mathrm{C}_{1}$. If the volume corresponding to the shaded area in Fig. 10 has slided into the center and the inclination of the surface has been maintained at the initial angle $\theta_{0}$, this volume is given by Eq. (24).

$$
V_{1}=\pi \int_{0}^{Z_{1}} r_{1}(z)^{2} d z+\pi \int_{Z_{1}}^{Z_{2}}\left\{r_{1}(z)^{2}-r_{2}(z)^{2}\right\} d z
$$

Figure 11 shows the relation between $\Delta v$ and the slided volume $\left(V_{1}\right)$. It is found that, when $\Delta v=0.5$, $1.4 \mathrm{~m}^{3}(2.5 \mathrm{t})$ of charged ore slides during the time from dumping to reaching $\mathrm{CL}$, which is $2.7 \%$ of ore for a charge.

\section{Discussion}

1. Comparison of Calculated Results with Observed Data of the Peripheral Layer Thickness

In Fig. 12, the calculated results are compared with the observed relation between $v^{*}$ and the layer thickness shown in Fig. 4. Here, the parameter $\Delta v$ is related to $v^{*}$ as follows: The average descending

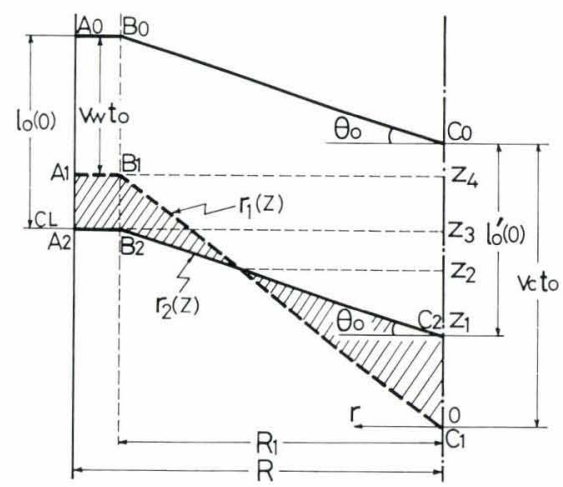

Fig. 10. A schematic drawing of ore volume slided into the central part at stock line 
rate is written as Eq. (25).

$$
v_{a v}=\frac{2 \pi}{\pi R^{2}} \int_{0}^{R} v(r) \cdot r \cdot d r=v_{w}+\frac{1}{3}\left(\frac{R_{1}}{R}\right)^{2}\left(v_{c}-v_{w}\right)
$$

Dividing both sides by $v_{w}, v^{*}$ is obtained as Eq. (26).

$$
v^{*}=\frac{v_{w}}{v_{a v}}=\frac{1}{1+(1 / 3)\left(R_{1} / R\right)^{2} \Delta v}
$$

With regard to the coke layer, in the region of $v^{*}<$ 1 , the calculated layer thickness is constant because the thickness is decided by the coke base and $\Delta \theta$ from the assumption that the inclination of ore surface is maintained at constant by sliding into the center, and the observed data also shows this tendency. In the region of $v^{*}>1$, as the inclination of ore layer on arrival at CL becomes smaller with an increase in the

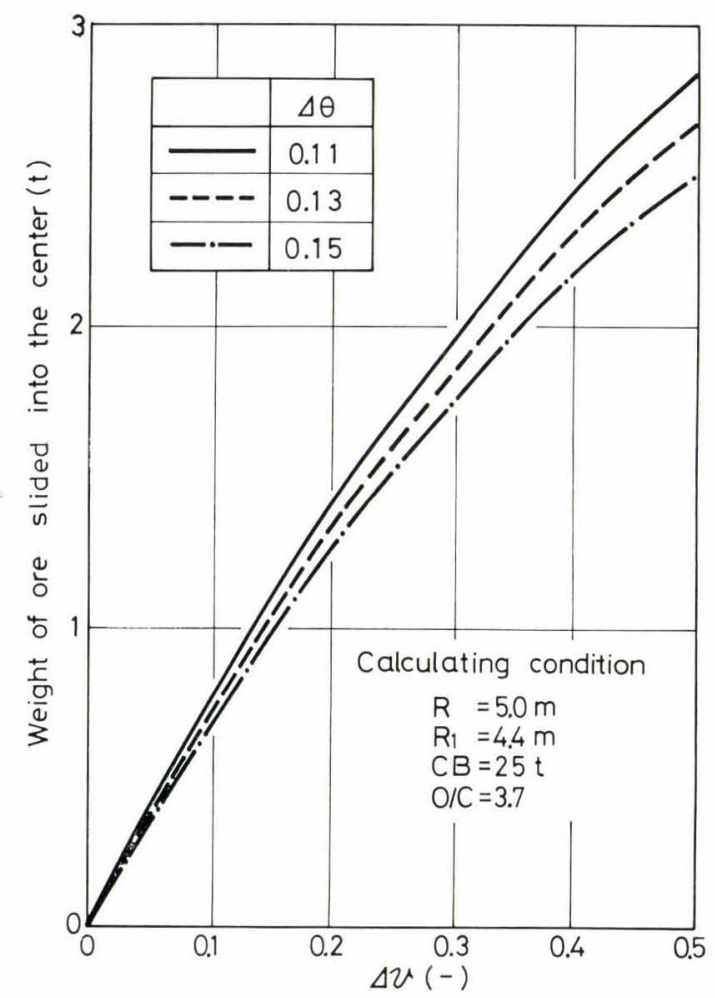

Fig. 11. Relation between $\Delta v$ and weight of ore slided into the center peripheral descending rate, the calculated thickness at the periphery is increased with $v^{*}$, which gives good agreement with the observed results.

As to the ore layer, in the case of $v^{*}>1$, the calculated thickness at the periphery becomes larger with $v^{*}$ in the same way as the coke layer, which is in good agreement with the observed results. In the case of $v^{*}<1$, the smaller $v^{*}$ is, the steeper the inclination of coke surface is. Therefore the next ore should be more charged in the central part and the peripheral layer thickness results in decrease.

When ore slides into the center, as mentioned above, the charging level probe is not able to detect the actual descending rate $\left(v_{w}\right)$. In this case, comparing the calculated results with the observed ones, it is necessary to correct the apparent descending rate obtained by a charging level probe. But in this work the measuring data are adopted as they are, because the traceability of charging level probe is uncertain. Although the observed data show a little dispersion, the calculated results are in qualitative agreement with the observed data.

From these results, it is confirmed theoretically that the radial distribution of burden descending rate has an effect on the thickness of charged layer.

\section{Trajectory of Charging Level Probe}

The trajectory of charging level probe is significant to understand the burden descending conditions.

Figure 13 shows the typical trajectories in the cases of $G T_{1}<1$ and $7<G T_{1}$. In the case of $7<G \mathcal{T}_{1}$, there exists a linear relation between the depth of charging level probe and the time elapsed. It is suggested that the burden descends smoothly at a constant velocity. When $G T_{1}<1$, the trajectory shows a curved line and the descending rate seems to rise with the time elapsed.

Assuming that the charging materials slide into the center with the burden descent, the velocity vector $\mathbf{V}$ of the charging level probe should arise radial component $V_{r}$ as shown in Fig. 14 (a).

From Fig. 14 (a), the descending trajectory could be expressed as Eq. (27).

$$
S(t)=\sqrt{ }\left(L+V_{z} \cdot t\right)^{2}+\left(V_{r} \cdot t\right)^{2}-L
$$

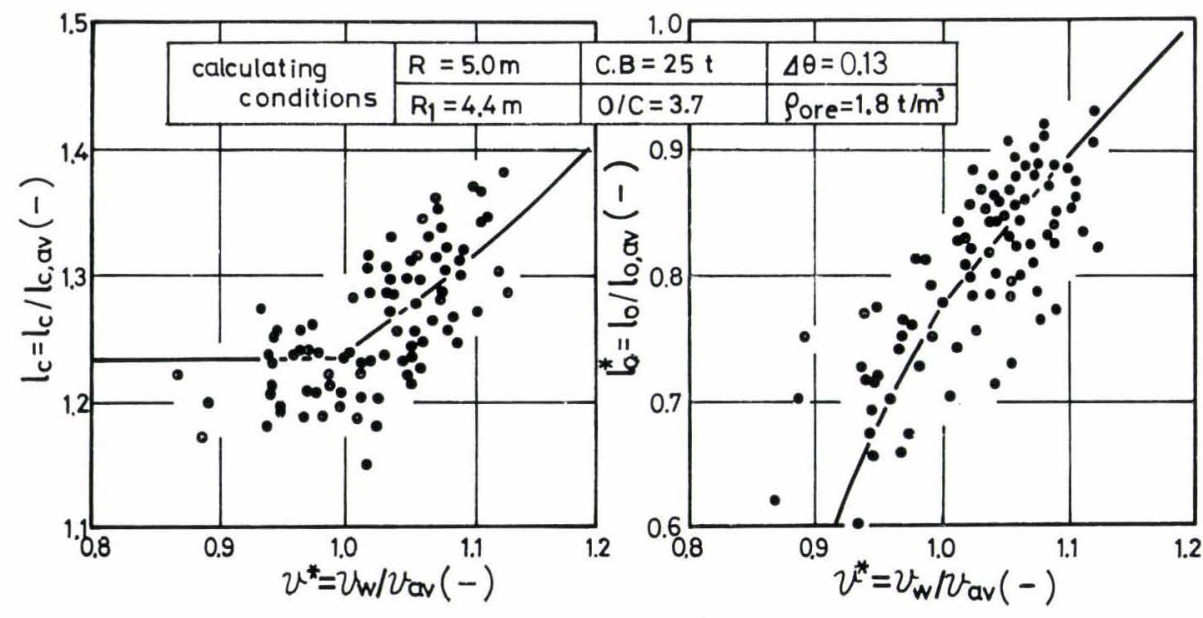

Fig. 12.

Comparison of calcualted layer thickness with measured values 


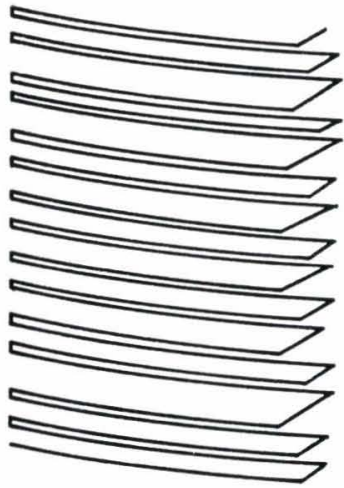

(a) $7<\mathrm{GT}_{1}$

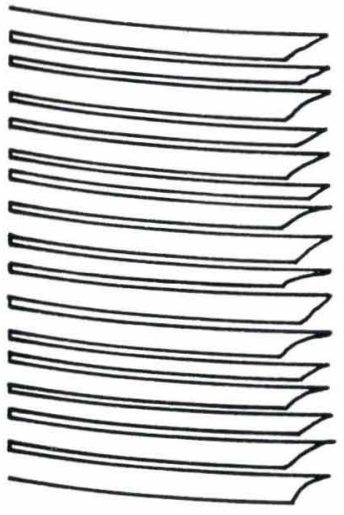

(b) $\quad G T_{1}<1$
Fig. 13. Descending trajectory of charging level probe in blast furnace

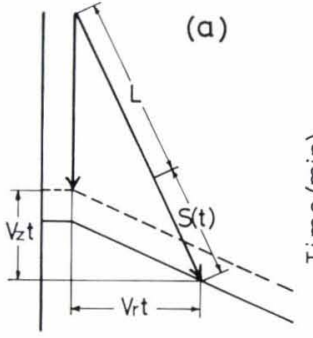

$S(t)=\sqrt{\left(L+V_{z} t\right)^{2}+\left(V_{t} t\right)^{2}}-L$ (b)

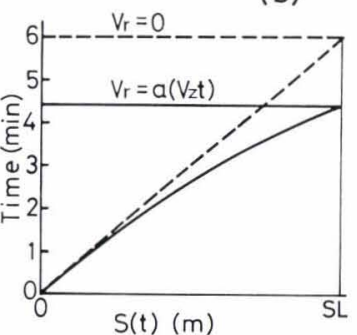

$S(t)(m)$
Fig. 14. Analysis of descending trajectory of charging level probe

Figure 14 (b) shows the trajectory calculated from Eq. (27), assuming that $V_{r}$ is proportional to the descending distance.

Clearly from Fig. 14 (b), when the charging level probe descends vertically $\left(V_{r}=0\right)$, as depicted by broken line, the descent distance is proportional to the time elapsed. When the sliding of materials into the center takes place, the trajectory should show a curved line and the burden surface seems to arrive at the charging level (CL) in a rather shorter time.

It is found that calculated trajectories are quite similar to the observed ones in Fig. 13.

\section{Relationship between $G T_{1}$ and the Thermal Conditions of the Blast Furnace}

It has been found that the $G T_{1}$ is closely related to the burden descent and that $v^{*}$ has a great effect on the distribution of charged layer thickness.

As mentioned above, the variation of layer thickness distribution leads to the change of radial distribution of ore/coke ratio, which suggests to influence the thermal condition of the furnace. Representing the thermal condition by the temperature of hot metal, the temperature of hot metal was varied in 6 to $8 \mathrm{hr}$ after the sudden change of gas temperature pattern as shown in Figs. 15 (a) and (b).

Figure 15 (a) shows that the temperature of hot metal began to fall in 6 to $8 \mathrm{hr}$ after a rapid decrease of $G T_{1}$. Though the thermal compensation was tried by raising the blast temperature, the temperature of hot metal could not be raised, and fell down to
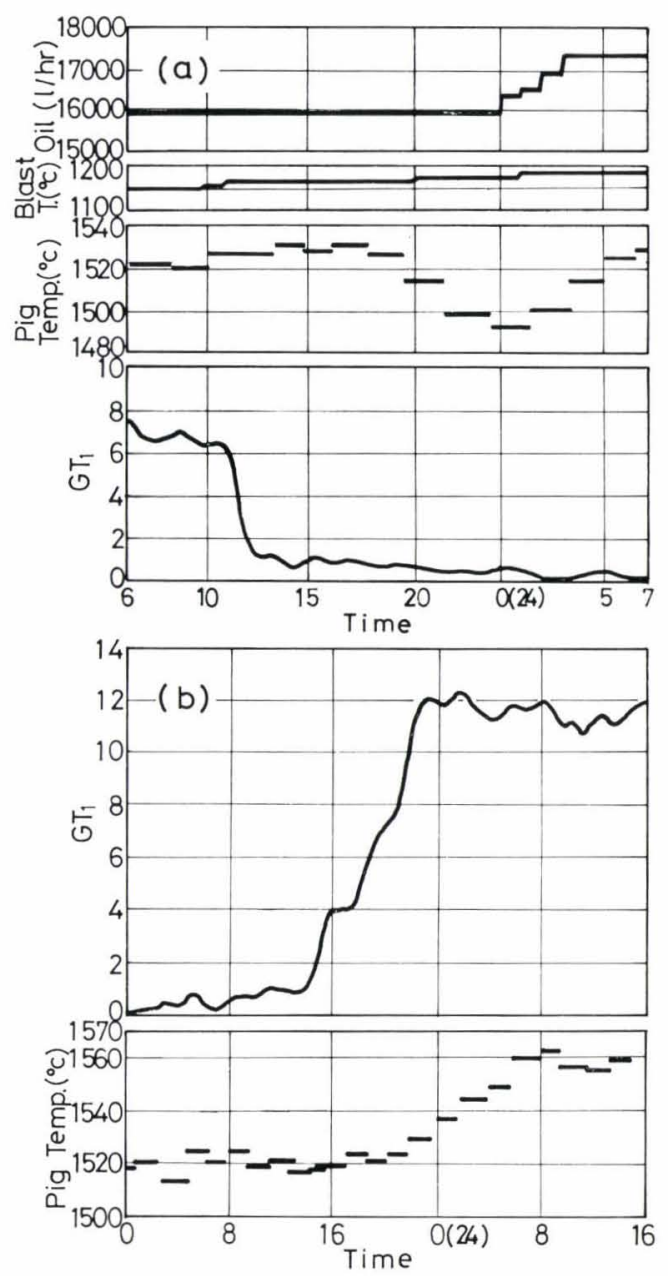

Fig. 15. Relationship between pig iron temperature and $G T_{1}$ index

$1490^{\circ} \mathrm{C}$. Then the temperature of hot metal was raised by increasing the fuel-oil injection under the constant oxygen enrichment in order to extend the residence time of the burden. However, $G T_{1}$ remained smaller.

Figure 15 (b) shows the reverse case. In 6 to $8 \mathrm{hr}$ after $G T_{1}$ rose suddenly, the temperature of hot metal is raised at $1560^{\circ} \mathrm{C}$.

An example of regulating the thermal condition of blast furnace by applying the above results is shown in Fig. 16. As a rapid decrease of $G \mathcal{T}_{1}$ suggests that the temperature of hot metal would fall after 6 to $8 \mathrm{hr}$, soon after the sudden change of $G T_{1}$ more fuel oil was injected with constant oxygen enrichment. Moreover, blast volume was increased to lower the heat content ratio of solid to gas based on the analyzed results that the bosh gas volume per unit hot metal was decreased when $G T_{1}$ was small.

By the modification of these blowing conditions, the temperature of hot metal remained constant. $G T_{1}$ decreased temporarily; however, $G T_{1}$ was recovered to the central flow type after $10 \mathrm{hr}$.

Thus, $G \mathcal{T}_{1}$ is closely related to the temperature of hot metal, furthermore $G T_{1}$ changes prior to the temperature of hot metal. It has been found that $G T_{1}$ is the available index to control the temperature of hot metal. 


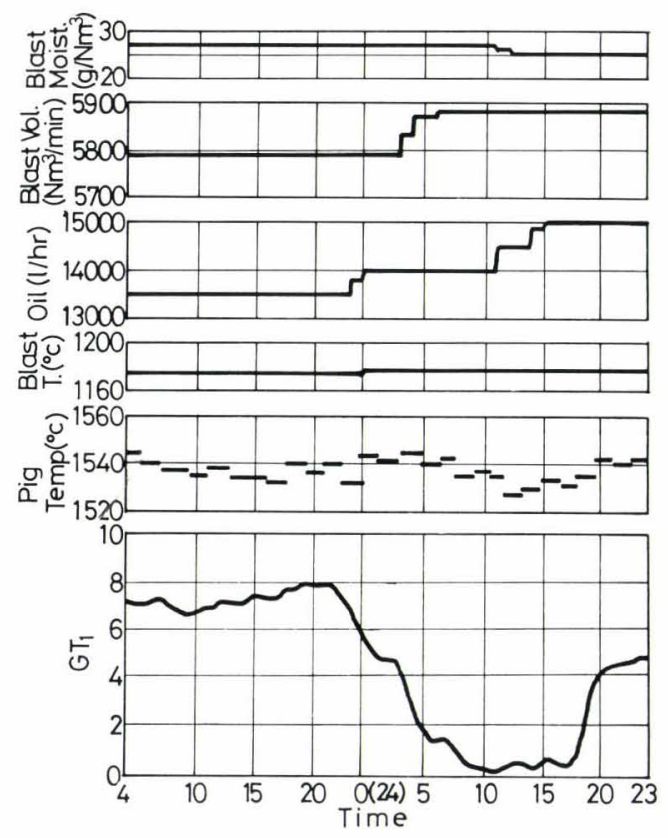

Fig. 16. Effect of blast condition against $G T_{1}$ changing on pig iron temperature

\section{Conclusion}

The gas temperature distribution has been studied with the operational data of Kakogawa No. 2 blast furnace in Kobe Steel, Ltd.

$G T_{1}$ index has been defined to indicate the gas temperature distribution at the throat, and the relation between $G T_{1}$ and the various operating factors have been analyzed.

Theoretical analysis has been made to calculate the layer thickness of the burden at the throat considering the radial distribution of burden descending rate. The sliding of burden material in the center has been discussed based on the trajectory detected by a charging level probe, and the material volume slided into the central part has been quantitatively estimated. Furthermore, the relationship between $G T_{1}$ and the thermal condition of the blast furnace has been investigated.

Then the followings are clarified.

(1) The radial distribution of the gas temperature at the throat is closely related to the stability of the furnace performance and the permeability in the furnace.

(2) There exists the radial distribution of the burden descending rate, which changes the temperature distribution at the throat.

(3) It is theoretically confirmed that the layer thickness could be varied by the change in the radial distribution of burden descent. The results obtained from the theoretical analysis are in good agreement with the operational results of the blast furnace.

(4) The temperature of hot metal should be varied in 8 to $10 \mathrm{hr}$ after the sudden change of $G T_{1}$, that is, the variation of $G T_{1}$ should precede that of the temperature of hot metal. Therefore, $G T_{1}$ can be an available index for the previous control of the thermal condition of the blast furnace.

\section{Nomenclature}

$A:$ sectional area of the throat $\left(\mathrm{m}^{2}\right)$

$C_{1}, C_{2}:$ constant

$\mathrm{C}_{\mathrm{B}}$ : coke base ( $\mathrm{kg} /$ charge)

$F$ : fluctuation index of blast pressure $\left(\mathrm{Kg} / \mathrm{m}^{2}\right.$. sec)

$G T_{1}$ : index of gas temperature profile at the throat (-)

$i$ : sampling number (-)

$l_{\mathrm{c}}, l_{\mathrm{o}}$ : peripheral layer thickness of coke and ore, respectively $(\mathrm{m})$

$l_{c}^{\prime}, l_{0}^{\prime}$ : central layer thickness of coke and ore, respectively $(\mathrm{m})$

$l_{\mathrm{c}, a v}, l_{\mathrm{o}, a v}:$ average layer thickness of coke and ore, respecitively $(\mathrm{m})$

$l_{c}^{*}, l_{\mathrm{o}}^{*}:$ dimensionless layer thickness of coke and ore, respectively (-)

$\mathcal{N}$ : charging times (charges/day)

$n:$ sum of samples (-)

$\mathrm{O} / \mathrm{C}$ : weight ratio of ore to coke $(-)$

$P_{B}:$ blast pressure $\left(\mathrm{kg} / \mathrm{m}^{2}\right)$

$\mathrm{P}: \quad$ parameter $\left[=\left(\mathrm{R}_{1} / \mathrm{R}\right)^{2} / 3\right](-)$

$R$ : throat radius $(\mathrm{m})$

$R_{1}$ : radial position at the break point of $\mathrm{M}$ shape burden surface $(\mathrm{m})$

$r$ : radial distance $(\mathrm{m})$

T: gas temperature at the throat $\left({ }^{\circ} \mathrm{C}\right)$

$t:$ time (sec)

$t_{0}$ : time elapsed for reaching charging level (sec)

$V_{\mathrm{e}}, V_{\mathrm{o}}$ : charging volume of coke and ore, respectively $\left(\mathrm{m}^{3}\right)$

$V_{1}$ : ore volume sliding into the center $\left(\mathrm{m}^{3}\right)$

$v_{a v}:$ average descending rate $(\mathrm{m} / \mathrm{sec})$

$v_{c}:$ central descending rate $(\mathrm{m} / \mathrm{sec})$

$v_{w}:$ peripheral descending rate $(\mathrm{m} / \mathrm{sec})$

$v^{*}$ : dimensionless descending rate $(-)$

$\beta$ : increase of inclination (rad)

$\theta_{\mathrm{c}}, \theta_{\mathrm{o}}$ : surface inclination of coke and ore layer, respectively ( $\mathrm{rad})$

$\rho_{\mathrm{c}}, \rho_{\mathrm{o}}$ : bulk density of coke and ore, respectively $\left(\mathrm{kg} / \mathrm{m}^{3}\right)$

$\Delta P_{i}$ : variation of blast pressure $\left[=P_{B, i}-P_{B, i-1}\right]$ $\left(\mathrm{Kg} / \mathrm{m}^{2}\right)$

$\Delta v$ : dimensionless parameter of radial distribution of burden descent $\left[=\left(v_{c}-v_{w}\right) / v_{w}\right](-)$

$\Delta \theta:$ difference of inclinations $\left[=\tan \theta_{\mathrm{c}}-\tan \theta_{\mathrm{o}}\right]$

\section{REFERENCES}

1) K. Tashiro, Y. Kase, Y. Kanayama and Y. Okuno: Tetsuto-Hagané, 61 (1975), A53.

2) Report of Ironmaking Committee of the Joint Research Society, ISIJ., No. 44-19-Research theme, (1974).

3) M. Higuchi: Tetsu-to-Hagané, 61 (1975), A61.

4) Japanese patent 18 months' publication, (1974), Sho-4959717.

5) K. Narita, S. Inaba, K. Okimoto, I. Kobayashi, M. Shimizu, T. Uenaka, T. Yabata and S. Tamada: Tetsu-toHagané, 63 (1977), S435. 